GLOBAL WATER PATHOGEN PROJECT

PART THREE. SPECIFIC EXCRETED PATHOGENS: ENVIRONMENTAL AND EPIDEMIOLOGY ASPECTS

\title{
BALANTIDIUM COLI
}

\author{
Francisco Ponce-Gordo \\ Complutense University \\ Madrid, Spain
}

Kateřina Jirků-Pomajbíková

Institute of Parasitology Biology Centre, ASCR, v.v.i.

Budweis, Czech Republic 


\section{Copyright:}

\section{cc) (i) (2) \\ BY SA}

This publication is available in Open Access under the Attribution-ShareAlike 3.0 IGO (CC-BY-SA 3.0 IGO) license (http://creativecommons.org/licenses/by-sa/3.0/igo). By using the content of this publication, the users accept to be bound by the terms of use of the UNESCO Open Access Repository (http://www.unesco.org/openaccess/terms-use-ccbysa-en).

\section{Disclaimer:}

The designations employed and the presentation of material throughout this publication do not imply the expression of any opinion whatsoever on the part of UNESCO concerning the legal status of any country, territory, city or area or of its authorities, or concerning the delimitation of its frontiers or boundaries. The ideas and opinions expressed in this publication are those of the authors; they are not necessarily those of UNESCO and do not commit the Organization.

\section{Citation:}

Ponce-Gordo, F., Jirků-Pomajbíková, K. (2017). Balantidium coli. In: J.B. Rose and B. Jiménez-Cisneros (eds), Water and Sanitation for the 21st Century: Health and Microbiological Aspects of Excreta and Wastewater Management (Global Water Pathogen Project). (R. Fayer and W. Jakubowski (eds), Part 3: Specific Excreted Pathogens: Environmental and Epidemiology Aspects - Section 3: Protists), Michigan State University, E. Lansing, MI, UNESCO. https://doi.org/10.14321/waterpathogens.30

Acknowledgements: K.R.L. Young, Project Design editor; Website Design: Agroknow (http://www.agroknow.com)

Last published: October 18, 2017 


\section{Summary}

To date, Balantidium coli is the only ciliate protozoan reported to infect the gastrointestinal track of humans. During its life cycle, two stages exist: the active trophozoite stage which inhabits the hindgut, and the resting/resistant cyst stage which is shed with the feces and is the transmissible stage to new hosts. The parasite can infect a wide range of mammals, pigs being the main reservoir. The organism has also been found in some birds.

In most cases, $B$. coli is not considered a public health problem because infections are usually asymptomatic; however, in some (still not clearly determined) circumstances the parasite could invade the intestinal mucosa causing a disease known as balantidial dysentery (balantidiasis) which could be fatal. Transmission from one infected individual to others is by a fecal-oral route in which contaminated drinking water or food are the main modes of transmission. Close contact with pigs and poor condition of the water sources are the main risk factors associated with the infection by the parasite.

Control measures includes the identification and treatment of infected people, the safe disposal of excreta (both of human and animal origin), avoiding the use of night soil as fertilizer for vegetables to be consumed raw, and the improvement in the quality of the water sources. There have not been any specific studies about $B$. coli cyst survival time in the environment or about specific inactivation processes during wastewater or drinking water treatment.

The protozoan ciliates of the genus Balantidium are transmitted by a fecal-oral route in which cysts are the infective stage. Balantidium cysts can be present in temperate and tropical surface waters worldwide. Among the species in this genus, there is only one infecting humans, Balantidium coli, and no subspecies, serotypes, or genetically diverse types have been named to date. The main reservoir of this species is swine. Human infections are related worldwide in relation to low sanitation or to contamination of drinking water sources with human and animal (especially swine) feces. Worldwide prevalence is low, estimated less than $1 \%$, with most cases reported in a few endemic areas in which prevalence could rise up to $30 \%$. Most infections are asymptomatic, but the organism could in some cases produce a severe infection and even the death of the host, usually associated with other concurrent illness. Waterborne transmission has been documented in some cases

\section{Epidemiology of the disease and pathogen}

\subsection{Global burden of disease}

\subsubsection{Global distribution}

Balantidium coli is reported worldwide although it is more common in temperate and tropical regions (Areán and Koppisch, 1956). The Philippines, Papua New Guinea, some Pacific Islands, some regions of Central and South America and central Asia are considered endemic areas (Fletcher et al., 2012; Kline et al., 2013; Owen, 2005; Schuster and Ramirez-Avila, 2008; Zaman, 1978).

In humans, the overall prevalence is estimated to be 0.02 to 1\% (Areán and Koppisch, 1956; Boonjaraspinyo et al., 2013; Schuster and Ramirez-Avila, 2008; Walzer and Healy, 1982). It is possible that these numbers are an underestimation of the real situation as the parasite is considered usually asymptomatic and most reports and statistics are based on data from symptomatic or compromised patients (Cooper and Guderian, 1994; McCarey, 1952; Nuti et al., 1979; Walzer et al., 1973). In endemic areas of South America the prevalence has been reported to be 1 to 12\% (Areán and Koppisch, 1956; Devera et al., 1999; Esteban et al., 1998), and even near 30\% in Oceania (Kline et al., 2013; Walzer and Healy, 1982).

\subsubsection{Symptomatology}

It remains undetermined whether $B$. coli alone is pathogenic. Trophozoites inhabit the intestine, feeding on bacteria and other intestinal contents. In most cases, infections are asymptomatic and the infected host shows no clinical signs, suggesting that this ciliate is an opportunistic parasite that could take advantage of the weakened status of the host caused by other infections, lesions, or diseases. In such cases, the parasite could invade the intestinal wall causing the disease known as balantidiasis or balantidial dysentery. In the chronic form of the disease, the symptoms varied from unspecific abdominal disorders (diarrhea, abdominal pain) to cramping rectal pain, nausea and vomiting, whereas in the acute form these symptoms can be accompanied by mucus and blood in feces, and in severe cases, hemorrhages and perforation could occur resulting in parasite dissemination to other tissues or even in the death of the host (Areán and Koppisch, 1956; Neafie et al., 2011; Zaman, 1978). In most of the human patients with extraintestinal balantidiasis, a concurrent intestinal infection was usually not diagnosed (Anargyrou et al., 2003; Dhawan et al., 2013; Sharma and Harding, 2003; Vasilakopoulou et al., 2003) but a common characteristic was that they suffered from another illness such as diabetes, hepatic disorders, pulmonary and renal disorders, HIV infection or cancer (e.g. Anargyrou et al,. 2003; Clyti et al., 1998; Ferry et al., 2004; Karuna and Khadanga, 2014; Sharma and Harding, 2003; Vasilakopoulou et al., 2003). In the last few years, several cases have described the presence of $B$. coli in urine (Maino et al., 2010; Bandyopadhyay et al., 2013; Karuna and Khadanga, 2014; Khanduri et al., 2014), which stresses the importance of the examination of the urinary specimens.

The economic importance of balantidiasis is not well determined. In different studies it has been suggested that $B$. coli infections in animals could affect the development of 
the offspring directly (by causing mortality or reducing the weight gain; (Bauri et al., 2012; Bilic and Bilkei, 2006) or indirectly (i.e., by affecting the milk composition in the mother; Hinde, 2007). There are no data regarding the economic status of balantidiasis in humans.

\subsection{Taxonomic classification of the agent}

\subsubsection{Taxonomy}

Balantidium coli, the first intestinal protozoan formally identified in humans, is the largest protozoan inhabiting the human intestine and the only ciliate known to infect humans. The first formal description of this organism was reported as Paramecium coli by Malmsten in 1857 (Malmstein, 1857) but soon afterwards it was renamed as Balantidium coli by Stein in 1863 (Stein, 1863). Some proposals to change this name were made during the 20th century but they were not accepted until recently. Based on genetic analysis, Pomajbiková et al. (2013)(Pomajbíková et al., 2013) proposed to reclassify the human species in a new genus, as Neobalantidium coli for the homeothermic clade. Chistyakova et al. (2014) (Chistyakova et al., 2014) considered this name as a junior synonym of Balantioides coli, which was proposed by Alexeief (1931) (Alexeief, 1931). Because the nomenclature is under revision and to avoid confusion for the readers, we use the name that remains accepted worldwide and is commonly used in the scientific and medical literature - Balantidium coli.

The parasite has been described in a large number of host species (see "Reservoirs"). Based on morphological differences of specimens gathered from different host species, or from results of cross-infection studies, some researchers proposed that isolates from pigs, guinea pigs, camels and several non-human primates were different species (e.g., (Hegner, 1934; McDonald, 1922). Such morphological differences could be related to differences in growth conditions (Levine 1961); this nutrient-related variability has been also observed in in vitro cultures (Barbosa et al., 2015; Levine, 1940). Failures by some authors in cross-infections studies (i.e., see Awakian, 1937; Schumaker, 1930) have also led to the implication that an isolate was host specific and therefore a separate species.
But most of these species have been considered synonyms of B. coli (Levine, 1961; Levine, 1985). However, Balantidium suis from pigs and Balantidium caviae from the guinea pig have infrequently been used in publications until recently (Schuster and Ramirez-Avila, 2008). Recent genetic analysis with isolates from pigs, gorillas, and humans (Ponce-Gordo et al., 2008; Ponce-Gordo et al., 2011) have shown some genetic variability within the species, but this is not related to the origin of the isolates from a particular host species; in fact, these results and others obtained with isolates from different mammalian hosts including elk, African buffalo, several suid species (i.e., domestic pig, red river hog and South American tapir) and non-human primates (Pomajbíková et al., 2013; PonceGordo et al., unpublished) and from ostriches and rheas (Ponce-Gordo et al., 2008; Ponce-Gordo et al., 2011; PonceGordo et al., unpublished) indicate that only one species infects warm-blooded animals (mammals and birds), Balantidium coli.

\subsubsection{Physical description (morphology)}

Balantidium coli has two stages in its life cycle: the active, feeding, replicating stage (the trophozoite) that is found most commonly in the lumen of the large intestine, and the nonreplicating encysted stage (the cyst) that develops in the lower colon and is excreted in the feces. Trophozoites (Figure 1) are large (usually 100-150 $\mu \mathrm{m}$ in length; the size range varies somewhat according to different authors) and ovoid, with the entire cell surface covered by cilia. A mouth-like opening, the cytostome, is located in the anterior part of the cell. There is an elongate or kidney-shaped macronucleus usually located in the posterior part of the cell and a smaller, round micronucleus which usually overlaps the macronucleus and is not easily observable. Some vacuoles can also be seen in the cytoplasm. The cysts (Figure 2) are also large (40-60 $\mu \mathrm{m}$ in diameter); they are round and contain a single cell surrounded by a thick cyst wall. In stained cysts the macronucleus and some vacuoles can be easily identified and, occasionally, cilia can be seen. 


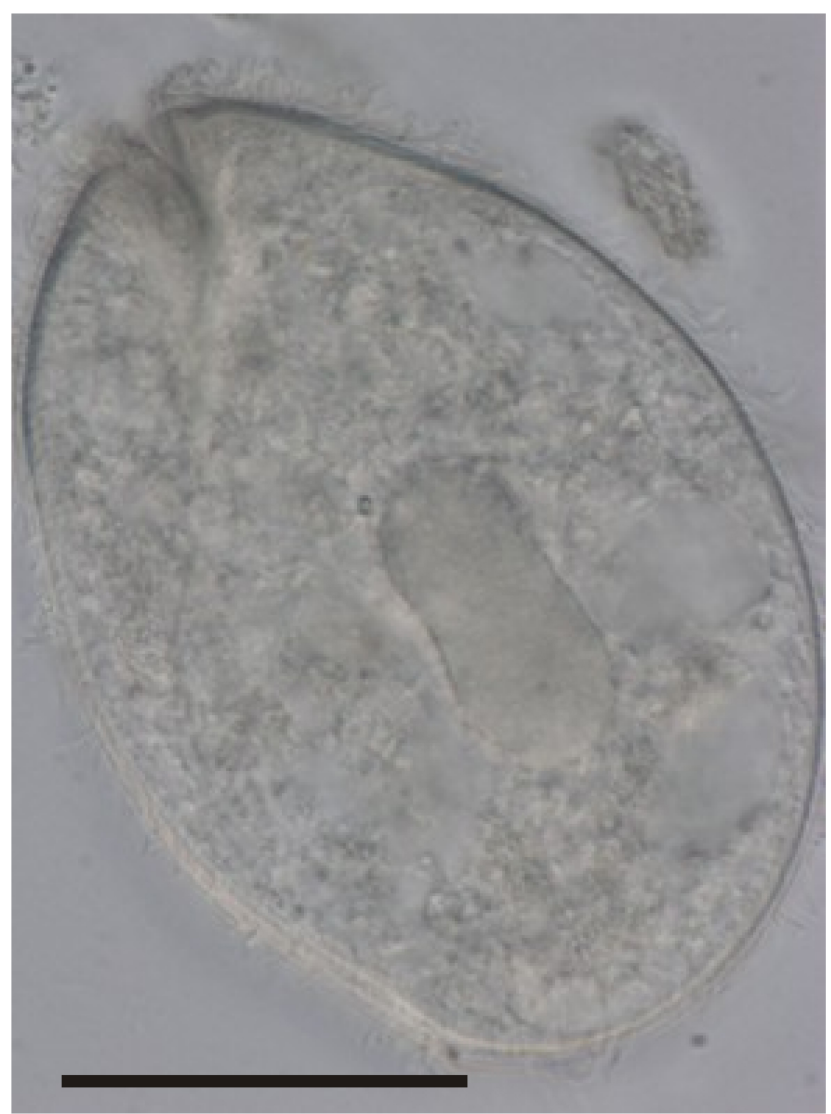

Figure 1 Balantidium coli trophozoite from a pig sample, unstained. Scale bar: $50 \mu \mathrm{m}$. 

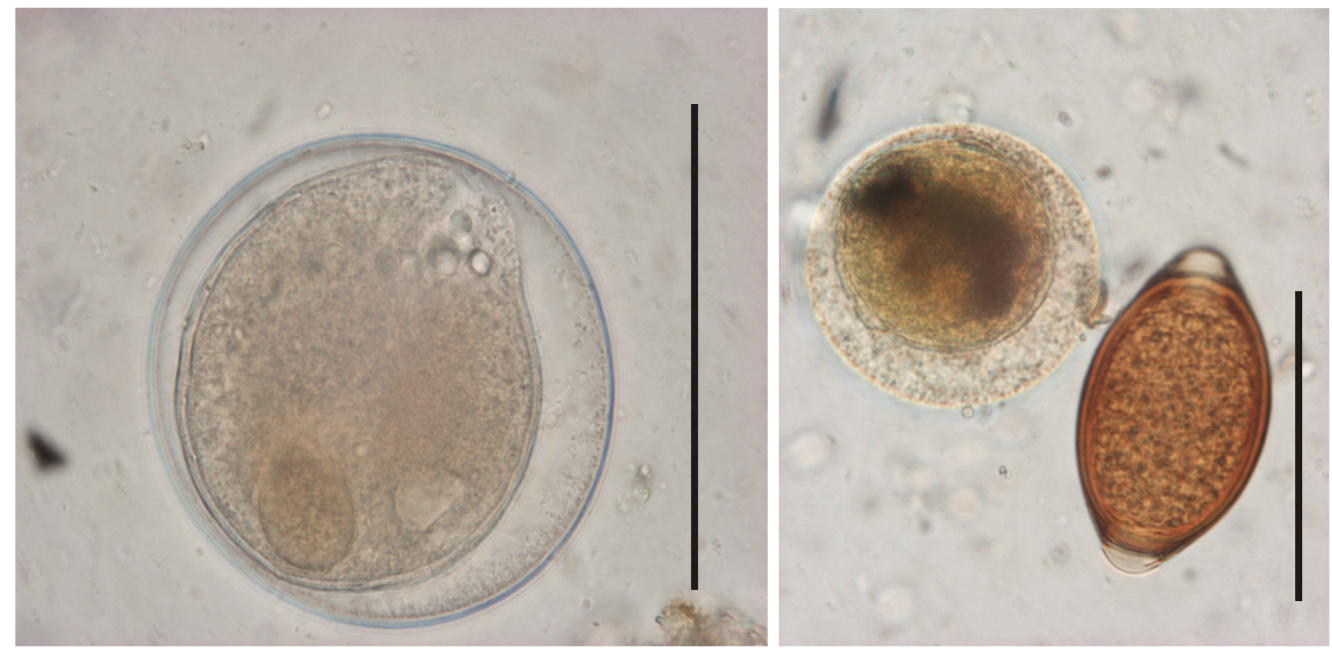

Figure 2 Balantidium coli cysts from a pig sample. Scale bar: $50 \mu \mathrm{m}$. Left: Unstained cyst. Right: Cyst stained with Lugol's iodine; an egg of Trichuris suis also shown for comparison purposes.

\subsection{Transmission}

\subsubsection{Routes of transmission}

Balantidium cysts are found in the feces of infected individuals. Balantidiasis is considered a waterborne and foodborne disease. The parasite is transmitted by the fecaloral route, with the cysts, and possibly but less likely the trophozoites, being ingested with fecally-contaminated water and food. Transmission by coprophagia could occur in animals, and this possibility has been suspected for some human infections, especially in asylums, orphanages, prisons and mental institutions (Areán and Koppisch, 1956; Giacometti et al., 1997; Schuster and Ramirez-Avila, 2008).

It has been considered that the trophozoites of $B$. coli cannot survive passage through the stomach (Schuster and Visvesvara, 2004) and the cysts were the only infective stage (Schuster and Ramirez-Avila, 2008). However, recent studies on captive great apes infected with $B$. coli suggest that trophozoites might also be infective (Pomajbíková et al., 2010). This possibility should be further investigated; if confirmed, trophozoites would likely need to be ingested within a few hours after excretion of the stools as their survival in the environment is limited (Areán and Koppisch, 1956), whereas cysts can survive with in the environment for ten days at room temperature (Rees, 1927) and for several weeks in pig feces, particularly if kept moist and away from direct sunlight (Schuster and Visvesvara, 2004). The cyst wall provides protection from stomach acid.

Outbreaks of balantidiasis are rare. Apart from two reports in mental institutions (Areán and Koppisch, 1956; Giacometti et al., 1997), only two other outbreaks were reported from southern Persia (McCarey, 1952) and from the Pacific island of Truk (Walzer et al., 1973; Walzer and Healy, 1982). In Persia, 87 cases were thought to be caused by human-to-human transmission among Muslims in an oil refinery town, whereas the outbreak in Truk affected 110 persons after a devastating typhoon that caused widespread contamination of water supplies with pig feces.

As a waterborne parasite, $B$. coli could be transmitted by drinking water but also by recreational water. In countries with high sanitation standards, transmission is mainly due to an occasional contamination (i.e., in swimming pools) or a process failure within water utilities (Bellanger et al., 2013), while in the developing world it could be the consequence of inadequate or insufficient sewage treatment and water supply systems that can be affected by adverse environmental conditions (e.g., the typhoon in Truk) (Plutzer and Karanis, 2016; Thompson and Smith, 2011).

\subsubsection{Reservoirs}

Balantidiasis is a zoonotic disease. The parasite has been described in a wide range of mammalian hosts other than humans, including non-human primates, pigs and wild boars, cattle, sheep, goats, camels, equids and rodents (Hegner, 1934; Levine, 1961; Levine 1985); Balantidium infecting ostriches and rheas might also be $B$. coli ( PonceGordo et al., 2008; Ponce-Gordo et al., 2011). On the other hand, Balantidium species from poikilothermic hosts have been erroneously reported as $B$. coli and their hosts (i.e., turtle, cockroaches) have been incorrectly listed as suitable hosts of B. coli (i.e., Areán and Koppisch, 1956; Neafie et al., 2011).

The most important reservoirs are the domestic pig and 
wild boars. Other hosts potentially important in the transmission of $B$. coli to humans are rodents, wild boars, sheep, goats, camels and horses. Domestic pigs are infected worldwide with $B$. coli, with prevalence ranging from 50 to $100 \%$ of the animals examined (Hindsbo et al., 2000; Ismail et al., 2010; Schuster and Ramirez-Avila, 2008; Weng et al., 2005; Yatswako et al., 2007; Yin et al., 2015). In pigs, these ciliates are non-invasive and non-pathogenic (Schuster and Visvesvara, 2004). Among the studies, prevalence and the intensity of infection varied between gender and age groups and in some cases opposite results were found between the studies, but probably the main factors affecting infection rates were the management practices at each farm and the veterinary care (Schuster and RamirezAvila, 2008). In general, facilities with cement floors, adequate cleaning protocols, and sewage disposal reduced the prevalence among pigs (Ismail et al., 2010; Giarratana et al., 2012; Weng et al., 2005; Yatswako et al., 2007; ).

There are very few studies on the prevalence of $B$. coli in wild boars and feral pigs. The data available indicate that prevalences are lower than in domestic pigs, ranging from 4 to $70 \%$ depending on the study (Navarro-Gonzalez et al., 2013; Solaymani-Mohammadi et al., 2004). Other suids such as the Central American tapir has been found infected with B. coli (Cruz Aldan et al., 2006), but its epidemiological importance in relation to the transmission of $B$. coli to humans is unknown.

The epidemiology of $B$. coli in some Muslim countries has not been clearly determined, but reservoirs other than pigs have been proposed to be of local importance. Although pig farming is forbidden in Muslim countries, human balantidiasis exists in some regions, such as Iran (Solaymani-Mohammadi et al., 2005a; WHO 1979). It has been proposed that wild boars might act as the main reservoirs (Solaymani-Mohammadi et al., 2005a; Solaymani-Mohammadi et al., 2005b); other authors have suggested camels (Cox 2005), donkeys (Khan and Fallon 2013), and sheep and goats (Jamil et al., 2015). In Iran and neighboring countries, the parasite has been found in cattle and buffaloes (Mirzaei and Khovand 2015; Samad, 2011; Tarrar et al. 2008) but most of the reports have been based on the cyst stage, which is indistinguishable from the cattle ciliate Buxtonella sulcata (Sultan et al., 2013) so the importance of ruminants (cattle and buffaloes) as reservoirs of $B$. coli should be considered with caution.

Balantidium coli has been found in several rodent species. Rats have been considered as a possible source of infection of $B$. coli for humans and as a source of spreading the cysts in the environment (Awakian, 1937; Bogdanovich, 1955; Schumaker, 1930). Other rodents, such as the lowland paca (Cuniculus paca) which is raised as a source of proteins in some Central American countries, can harbor this ciliate Matamoros et al. (Matamoros et al., 1991) gave a prevalence of $5.7 \%$ in farmed pacas in Costa Rica and may play a role in the transmission of the parasite to humans in these regions.

\subsubsection{Incubation period}

There are no data on prepatent and incubation periods of $B$. coli in humans. According to experimental infections in piglets and non-human primates, the incubation period ranges from 3 to 6 days (Yang et al., 1995).

\subsubsection{Period of communicability}

The infectious dose or dose-response for trophozoites or cysts is not known. The disease is communicable (infectious) for as long as organisms are excreted, but it should be noted that in chronic balantidiasis the parasite is identified in the stools only sporadically (Areán and Koppisch, 1956). Cysts can survive much longer (weeks) outside the host body whereas trophozoites die at a faster rate (hours) (Areán and Koppisch 1956; Schuster and Visvesvara, 2004). This information is important for understanding human-to-human transmission, because cysts are rarely detected in human feces and trophozoites are often found in cases of dysentery (Areán and Koppisch, 1956; Kennedy and Stewart, 1957).

\subsubsection{Population susceptibility}

Persons working with animals appear at greatest risk of acquiring balantidiasis, especially those in contact with pigs (the main reservoir host of $B$. coli). Pig-to-human transmission was recorded in areas where humans live in close proximity with domestic pigs and even share habitation (Ferry et al., 2004; Sharma and Harding, 2003). In most cases, people at greatest risk live in poor hygienic conditions (Barnish and Ashford, 1989; Esteban et al., 1998; Owen, 2005). Others at risk work in abattoirs where pig intestines are handled; farmers working with pig feces; zookeepers working with apes carrying $B$. coli infections, or are veterinarians or veterinary students (Anargyrou et al., 2003; Schuster and Visvesvara, 2004). In regions where pigs are not reared such as Muslim countries, the contact with other reservoirs such as wild boars, camels, small ungulates or equids could be the source of infection. In all cases, a poor hygienic environment or poor personal hygiene (see below - hygiene measures) would facilitate both the animal-to-human and the human-to-human transmission.

Another important factor is the health status of the person, which is of paramount importance for the onset of the infection and of the disease. This includes the physical condition, concurrent pathologies, immunological status and immunodepression (Anargyrou et al., 2003; Maino et al., 2010; Vasilakopoulou et al., 2003; Yazar et al., 2004; ) and diet (nutritional status) of each person (Schovancová et al., 2013). Balantidium coli is usually detected in persons with other infectious agents (other protozoa, helminths, bacteria, viruses), with systemic diseases, or suffering malnourishment. All of these conditions complicate the medical management and the prognosis (Walzer and Healy, 1982). Although there is no conclusive evidence that these other infections render the host more susceptible to $B$. coli (Schuster and Ramirez-Avila 2008), the extraintestinal locations of the parasite are usually associated with other concurrrent illness (e.g., Anargyrou et al., 2003; Clyti et al., 1998; Ferry et al., 2004; Karuna and Khadanga, 2014; Khanduri et al., 2014; Sharma and Harding, 2003; 
Vasilakopoulou et al., 2003). Other factors that might facilitate balantidiasis include the virulence of $B$. coli subpopulations (still not confirmed) and the number of infecting forms ingested (Schuster and Ramirez-Avila, 2008).

\subsection{Population and individual control measures}

The populations at greatest risk are people living in close contact with reservoir hosts (as in many rural areas), people living in poor sanitation environments with limited, unconditioned, or absent adequate infrastructures for water supply and sewage disposal; people with poor hygienic habits, those at low socio-economical levels, and those residents and workers in institutions (as asylums, orphanages, prisons and mental institutions) where hygienic supervision is inadequate (Schuster and RamirezAvila, 2008; Yatswako et al., 2007). Human infection is rare in temperate areas and in industrialised countries (Ferry et al., 2004). In France a clinical case of balantidiasis in a not immunocompromised patient, who lived alone, with no history of travel or chronic inflammatory bowel disease was recently reported (Bellanger et al., 2013). The patient was not working in contact with animals. He reported having been on a hike the previous weekend during which he had drunk water through a polyurethane hydration pouch bladder. The patient insisted that he did not refill the hydration system during the hike. In the authors' opinion, the persistence of residual water in the patient's hydration pouch bladder was the source of the contamination (Bellanger et al., 2013).

\subsubsection{Hygiene measures - hand washing, disinfection}

The best means of protection against $B$. coli infection is by providing adequate clean water for drinking and other uses (Schuster and Ramirez-Avila, 2008). Because it is unrealistic to attempt to render reservoir animals (mainly pigs) $B$. coli-free, the best option is to keep animals and their feces away from contaminating water sources used for human consumption.

Chlorine, at concentrations normally used for ensuring water safety, is not effective against cysts of $B$. coli (Schuster and Ramirez-Avila, 2008). Water boiling is acceptable. Individual hygiene measures include washing hands with soap and clean water after being in contact with reservoir hosts or before handling food, and washing fruits and vegetables with clean water.

\subsubsection{Drug therapy}

Until the 1950s, about one third of persons with severe, acute balantidiasis would die (Areán and Koppisch, 1956). Since then, the use of antibiotics has clearly improved the prognosis and now most fatal cases are associated with another concurrent pathology. Balantidium coli infections are easily treated with antibiotic therapy, provided that the correct diagnosis is made in time (Knight, 1978). For humans, treatment consists of tetracycline (500 mg four times daily for 10 days; not recommended for pregnant women or for children under 8 years old), metronidazole
(750 mg three times daily for 5 days) or iodoquinol (640 mg three times daily for 20 days). It is advisable to give the patient a starch-free diet (Areán and Koppisch, 1956; Schovancová et al., 2013). Pigs (the main reservoir of $B$. coli) can be treated with oxytretracycline.

\section{Environmental Occurrence and Persistence}

\subsection{Detection methods}

Trophozoites of $B$. coli rapidly disappear outside the host (Areán and Koppisch, 1956) and only the cysts can be found in environmental samples. There are no specific or standardized methods for detection and those applied for other enteric protozoa and helminths can be used with $B$. coli.

In fecal samples, trophozoites can be easily detected by microscopy in saline smears by their size and their slow motion; in fixed samples, the morphology of the macronucleus can be easily recognized in both trophozoites and cysts in temporary smears stained with iodine. Other staining methods such as hematoxylin-eosin or trichrome are also useful. Cysts can be recovered using common coprological techniques (i.e., centrifugation methods for concentration). In samples from cattle and buffaloes, the diagnosis based on the identification of cysts should not be considered confirmatory because other ciliates (namely $B$. sulcata) with morphologically identical cysts could also be present. Complementary genetic analysis should be made in this case. For this purpose, the sequences corresponding to the ribosomal genes (the small subunit rDNA and the 5.8s rDNA, and the internal transcribed spacers -ITS- 1 and 2), although showing some genetic heterogeneity, can be used (Pomajbíková et al., 2013; Ponce-Gordo et al., 2008; Ponce-Gordo et al., 2011).

In environmental samples, the $B$. coli trophozoites would not be detectable (they disappear soon after the passage of the stools; Areán and Koppisch, 1956) and only the cysts would be found. However, it is not possible to differentiate on morphological grounds the cysts of $B$. coli from those of other Balantidium species (i.e., amphibian or fish balantidia), or even from those of other ciliates (as $B$. sulcata from cattle), and genetic analysis should be made to correctly identify the species.

\subsection{Data on occurrence in the environment}

\subsubsection{Feces}

Only very little data are known about intensity of infection of $B$. coli in pig or human samples, because generally it is difficult to choose an appropriate quantification method for ciliates. The only study by Růžicová et al. (2014) reported a few data on the intensity of infection of $B$. coli during calibration of the diagnostic and quantitative method FLOTAC ${ }^{\circledR}$ on both stages (Růžicová et al., 2014). The cysts were quantified in pig feces, whereas trophozoites in chimpanzees, which similarly as human feces contain trophozoite stages of $B$. coli. Despite it is optimized on chimpanzee feces, it can be 
used also for the detection and quantification of human infections.

\subsubsection{Sewage and sludge}

Few data are available on the presence of $B$. coli cysts in environmental samples, and care should be taken when interpreting the data available to date because they are based on unreliable cyst morphology (see "Detection methods").

The presence of the parasite has been reported in large numbers in sludge from a wastewater processing facility in Bahrain but the origin was uncertain, because prevalence among the residents served by the processing facility was found to be negligible (two positive patients out of over 18,000 samples examined) and pigs were absent (Amin, 1988). In another report, Balantidium cysts were found in the sewage water in Bangladesh; the samples were collected from different places and $B$. coli cysts were found in three places although in low intensity ranging between 5 to $7.5 \times 10^{4}$ stages cysts per liter (Khanum et al., 2012).

\subsubsection{Drinking waters}

The balantidiasis outbreak of Truk followed a typhoon affecting an island with primitive catchment water supplies, low hygiene standards, and high numbers of pigs in close contact with humans. The combination of these factors resulted in the contamination of the water supplies (Walzer et al. 1973). Apart from this outbreak derived from a catastrophic situation, there are no published outbreaks of balantidiasis in relation to water supplies. However, several authors have raised concerns about the risk of epidemics. In Australia, B. coli was detected in feral pig populations that were foraging and wallowing in major public drinking water catchments (Hampton et al., 2006). The authors speculated that chances of pathogens reaching the main water supply might be high.

In Hyderabad, India, $B$. coli cysts were detected in 61 of 232 water samples (26.3\% positive) collected in hostels, small restaurants, households, and various public places. The source of the contaminated samples was the water stored in overhead tanks and various other containers (Jonnalagadda and Bhat, 1995). In three districts in
Pakistan, B. coli cysts were detected in all three sources of drinking water used for examination (tap water, ponds, and drain water) with total prevalence 5.78\% (26/450) (Ayaz et al., 2011). A recent case report of a patient suffering from dysentery caused by $B$. coli related to water was reported in France by Bellanger et al. (Bellanger et al., 2013).

\subsubsection{Soil}

The only information about the occurrence of $B$. coli in the soil is from Nigeria where $B$. coli cysts were found in water and soil samples in two out of the seven pig farming areas (Yatswako et al., 2007). The prevalence of $B$. coli in pig population in the studied area ranged between 35.3 and $75.7 \%$ (207 samples positive for B. coli out of 402 collected samples in total).

In southwestern Nigeria, intestinal parasites, including $B$. coli, were detected on selected vegetables from open markets; the contamination was attributed to contaminated soil (Ogbolu et al., 2009). In Brazil several protozoan and helminth species including $B$. coli, were detected on fieldgrown strawberries although the prevalence was quite low (da Silva et al., 2014).

\subsection{Persistence}

There are few published data on the survival and viability of $B$. coli cysts in the environment. As mentioned above, the cysts could survive for several weeks in moist feces away from direct sunlight (Schuster and Visvesvara, 2004). Early studies in parasitology sugggest that the cysts survive in the environment for at least ten days at room temperature (Rees, 1927), whereas trophic ciliates can survive for as long as ten days in the environment (Zaman, 1978).

\section{Reduction by sanitation management}

There are no data available about the inactivation or removal of $B$. coli cysts by sanitation treatment processes. Because of their larger size (40-60 $\mu \mathrm{m}$ in diameter) it is possible that cysts are removed by sedimentation or filtration more so when compared to the removal of smaller protozoan cysts and helminth eggs. This suggests that the cysts will end up in the sludge and would remain an indicator of sanitation effectiveness for solid fecal waste treatment technologies. 


\section{References}

Aldan, C.E., Torres, L.I., Guiris Andrade, D.M., Sarabia, O.D. and Quintero, M.M. (2006). Parasites of the Central American tapir Tapirus bairdii (Perissodactyla: Tapiridae) in Chiapas, Mexico. Revista de Biología Tropical. 54, pp. $445-450$.

Alexeief, A. (1931). Sur quelques particularités de structure de Balantioides (nom. nov.) coli (Malmsten). Comptes Rendus des séances de la Société de BiologieComptes Rendus des séances de la Société de Biologie. 107, pp. 210-211.

Amin, O.M. (1988). Pathogenic micro-organisms and helminths in sewage products, Arabian Gulf, country of Bahrain. American Journal of Public Health. 78, pp. 314-315.

Anargyrou, K., Petrikkos, G.L., Suller, M.T.E., Skiada, A., Siakantaris, M.P., Osuntoyinbo, R.T. et al. (2003). Pulmonary Balantidium coli infection in a leukemic patient. American Journal of Hematology. 73, pp. 180-183.

Areán, V.M. and Koppisch, E. (1956). Balantidiasis: a review and report of cases. American Journal of Hygiene. 32, pp. 1089-1115.

Awakian, A. (1937). Studies on the intestinal protozoa of rats. II. Rats as carriers of Balantidium. Transactions of the Royal Society of Tropical Medicine and Hygiene. 31, pp. 93-98.

Ayaz, S., Khan, S., Khan, S.N., Bibi, F., Shamas, S. and Akhtar, M. (2011). Prevalence of zoonotic parasites in drinking water of three districts of Khyber Pakhtunkhwa Province, Pakistan. Pakistan Journal of Life and Social Sciences. 9, pp. 67-69.

Bandyopadhyay, A., Majumder, K. and Goswami, B.K. (2013). Balantidium coli in urine sediment: report of a rare case presenting with hematuria. Journal of Parasitic Disesaes. 37, pp. 283-285.

Barbosa, A., Pereira Bastos, O.M., Uchoa, C., Pissinatti, S., Filho, P.R.F., Dib, L.V. et al. (2015). Isolation and maintenance of Balantidium coli (Malmsteim, 1857) cultured from fecal samples of pigs and non-human primates. Veterinary Parasitology. 210, pp. 240-245.

Barnish, G. and Ashford, R.W. (1989). Occasional parasitic infections of man in Papua New Guinea and Iran Jaya (New Guinea). Annals of Tropical Medicine and Parasitology. 83, pp. 121-135.

Bauri, R., Ranjan, R., Deb, A. and Ranjan, R. (2012). Prevalence and sustainable control of Balantidium coli infection in pigs of Ranchi, Jahrkahnd, India. Veterinary World. pp. 94.

Bellanger, A.P., Scherer, E., Cazorla, A. and Grenouillet, F. (2013). Dysenteric syndrome due to Balantidium coli: a case report. New Microbiologica. 36, pp. 203-205.

Bilic, H.R. and Bilkei, G. (2006). Balantidium, Cryptosporidium and Giardia species infections in indoor and outdoor pig production units in Croatia. Veterinary Record. 158, pp. 61-61.

Bogdanovich, V.V. (1955). Spontaneous balantidiasis in rats. Meditsinskaia Parazitologiia I Parazitarnye Bolezni. 24, pp. 326-329. 
Boonjarsapinyo, S., Boonmars, T., Kaewsamut, B., Ekobol, N., Laummaunwai, P., Aukkanimart, R. et al. (2013). A crosssectional study on intestinal parasitic infections in rural communities, northeast Thailand. Korean Journal of Parasitology. 51, pp. 727-34.

Chistyakova, L.V., Kostygov, A.Y., Kornilova, O.A. and Yurchenko, V. (2014). Reisolation and redescription of Balantidium duodeni Stein, 1867 (Litostomatea, Trichostomatia). Parasitology Research. 113, pp. 4207-4215.

Clyti, E., Aznar, C., Couppie, P., M. Guedj, el., Carme, B. and Pradomaid, R. (1998). Un cas de conifection par Balantidium coli et VIH en Guyane Française. Bulletin de la Société de Pathologie Exotique. 91, pp. 309-311.

Cooper, P.J. and Guderian, R.H. (1994). Grastrointestinal illness associated with Balantidium coli infection in rural communities in Ecuador. Parasitología al Dia. 18, pp. 51-54.

Cox, F.E.G. (2005). Human balantidiasis in Iran: are camels reservoir hosts?. Trends in Parasitology. 21, pp. 553.

Da Silva, S.R.M., Maldonade, I.R., Ginani, V.C., Lima, S.A., Mendes, V.S., Azevedo, M.L.X. et al. (2014). Detection of intestinal parasites on field-grown strawberries in the Federal District of Brazil. Revista da Sociedade Brasileira de Medicina Tropical. 47, pp. 801-805.

Devera, R., Requena, I., Velasquez, V., Castillo, H., Guevara, R., De Sousa, M. et al. (1999). Balantidiasis in a rural community from Bolivar State, Venezuela. Boletín Chileno de Parasitología. 54, pp. 7-12.

Dhawan, S., Jain, D. and Mehta, V.S. (2013). Balantidium coli: an unrecognized cause of vertebral osteomyelitis and myelopathy. Journal of Neurosurgery: Spine. 18, pp. 310-313.

Esteban, J.G., Aguirre, C., Angles, R., Ash, L.R. and Mas-Coma, S. (1998). Balantidiasis in Aymara children from the northern Bolivian altiplano. American Journal of Tropical Medicine and Hygiene. 59, pp. 922-927.

Ferry, T., Bouhour, D., De Monbrison, F., Laurent, F., Dumouchel-Champagne, H., Picot, S. et al. (2004). Severe peritonitis due to Balantidium coli acquired in France. European Journal of Clinical Microbiology and Infectious Diseases. 23, pp. 393-395.

Fletcher, S.M., Stark, D., Harkness, J. and Ellis, J. (2012). Enteric protozoa in the developed world: a public health perspective. Clinical Microbiology Reviews. 25, pp. 420-449.

Giacometti, A., Cirioni, O., Balducci, M., Drenaggi, D., Quarta, M., De Federicis, M. et al. (1997). Epidemiologic features of intestinal parasitic infections in Italian mental institutions. European Journal of Epidemiology. 13, pp. 825-830.

Giarratana, F., Muscolino, D., Taviano, G. and Ziino, G. (2012). Balantidium coli in pigs regularly slaughtered at abattoirs of the province of Messina: hygienic observations. Open Journal of Veterinary Medicine. 02, pp. 77-80.

Hampton, J., Spencer, P.B.S., Elliot, A.D. and Thompson, R.C.A. (2006). Prevalence of Zoonotic Pathogens from Feral Pigs in Major Public Drinking Water Catchments in Western Australia. EcoHealth. 3, pp. 103-108. 
Hegner, R.W. (1934). Specifity in the genus Balantidium based on size and shape of body and macronucleus, with descriptions of six new species. American Journal of Hygiene. 19, pp. 38-67.

Hinde, K. (2007). Milk composition varies in relation to the presence and abundance of Balantidium coli in the mother in captive rhesus macaques (Macaca mulatta). American Journal of Primatology. 69, pp. 625-634.

Hindsbo, O., Nielsen, C.V., Andreassen, J., Willingham, A.L., Bendixen, M., Nielsen, M.A. et al. (2000). Age-dependent occurrence of the intestinal ciliate Balantidium coli in pigs at a Danish research farm. Acta Veterinaria Scandinavica. 41, pp. 79-83.

Ismail, H.A.H.A., Jeon, H.K., Yu, Y.M., Do, C. and Lee, Y.H. (2010). Intestinal parasite infections in pigs and beef cattle in rural areas of Chungcheongnam-do, Korea. Korean Journal of Parasitology. 48, pp. 347.

Jamil, M., Ijaz, M. and M. Ali, M. (2015). Prevalence, hematology and treatment of Balantidium coli among small ruminants in and Around Lahore, Pakistan. Kafkas Universitesi Veteriner Fakultesi Dergisi. 21, pp. 123-126.

Jonnalagadda, P.R. and Bhat, R.V. (1995). Parasitic contamination of stored water used for drinking/cooking in Hyderabad, Southeast Asian. Journal of Tropical Medicine and Public Health. 26, pp. 789-794.

Karuna, T. and Khadanga, S. (2014). A rare case of urinary balantidiasis in an elderly renal failure patient. Tropical Parasitology. 4, pp. 47.

Kennedy, C.C. and Stewart, R.C. (1957). Balantidial dysentery: A human case in Northern Ireland. Transactions of the Royal Society of Tropical Medicine and Hygiene. 51, pp. 549-558.

Khan, A.R. and Fallon, P.G. (2013). Helminth therapies: Translating the unknown unknowns to known knowns. International Journal of Parasitology. 43, pp. 293- 299.

Khanduri, A., Chauhan, S., Chandola, I., Mahawal, B. and Kataria, V. (2014). Balantidiosis: a rare accidental finding in the urine of a patient with acute renal failure. Journal of Clinical and Diagnostic Research for doctors. 8, pp. DD03-4.

Khanum, H., Khanam, S.S., Sultana, M., Uddin, M.H., Dhar, R.C. and Islam, M.S. (2013). Protozoan parasites in a wastewater treatment plant of Bangladesh. University Journal of Zoology, Rajshahi University. 31, Bangladesh Journals Online (JOL).

Kline, K., McCarthy, J.S., Pearson, M., Loukas, A. and Hotez, P.J. (2013). Neglected tropical diseases of Oceania: review of their prevalence, distribution, and opportunities for control. PLoS Neglected Tropical Diseases. 7, pp. e1755.

Knight, R. (1978). Giardiasis, isosporidiasis and balantidiasis. Clinics in Gastroenterology. 7, pp. 31-47.

Levine, N.D. (1985). Veterinary Protozoology. Iowa State University Press, Ames.

Levine, N.D. (1940). Changes in the dimensions of Balantidium from swine upon cultivation. American Journal of Hygiene. 32, pp. 1-7. 
Levine, N.D. (1961). Protozoan parasites of domestic animals and of man. Smithsonian Institution.

Maino, A., Garigali, G., Grande, R., Messa, P. and Fogazzi, G.B. (2010). Urinary balantidiasis: diagnosis at a glance by urine sediment examination. Journal of Nephrology. 23, pp. 732-737.

Malmsten, P.H. (1857). Infusorien als Intestinal-Thiere beim Menschen. Archiv für pathologische Anatomie und Physiologie und für klinische Medicin. 12, pp. 302-309.

Matamoros, Y., Velazquez, J. and Pashov, B. (1991). Parásitos intestinales del tepezcuinte, Agouti paca (Rodentia: Dasyproctidae) en Costa Rica. Revista de Biología Tropical. 39, pp. 173-176.

McCarey, A.G. (1952). Balantidiasis in South Persia. The BMJ. 1, pp. 629-631.

McDonald, J.D. (1922). On Balantidium coli (Malmsten) and Balantidium suis (sp. nov.) with an account of their neuromotor apparatus. University of California Publications in Zoology. 20, pp. 243-300.

Mirzaei, M. and Khovand, H. (2015). [An investigation on the prevalence of Balantidium coli in traditional farms of the Darab city in Fars Province (Iran)] (in Persian with English abstract). Journal of Experimental Animal Biology. 4, pp. 79-86.

Navarro-Gonzalez, N., Fernández-Llario, P., Pérez-Martín, J.E., Mentaberre, G., López-Martín, J.M., LavÃn, S. et al. (2013). Supplemental feeding drives endoparasite infection in wild boar in Western Spain. Veterinary Parasitology. 196, pp. 114-123.

Neafie, R.C., Andersen, E.M. and Klassen-Fischer, M.K. (2011). Balantidiasis. Meyers, W.M., Firpo, A., Wear, D.J. (Eds) Topics on the Pathology of protozoan and invasive arthropod diseases. Armed Forces Institute of Pathology, Washington. pp. 6 pp.

Nuti, M., Sanguigni, S. and de Bac, C. (1979). Osservazioni su di un focolaio endemico di balantidiasi (studio di 80 casi). Annali di Medicina Navale. 196, pp. 641-646.

Ogbolu, D.G., Alli, O.A., Ongunleye, V.F., Olusoga-Ogbolu, F.F. and Olaosun, I. (2009). The presence of intestinal parasites in selected vegetables from open markets in south western Nigeria. African Journal of Medicine and Medical Sciences. 38, pp. 319-324.

Owen, I.L. (2005). Parasitic zoonoses in Papua New Guinea. Journal of Helminthology. 79, Cambridge University Press (CUP). pp. 1-14.

Plutzer, J. and Karanis, P. (2016). Neglected waterborne parasitic protozoa and their detection in water. Water Research. 101, pp. 318- 332.

Pomajbíková, K., Oborník, M., Horák, A., Petrželková, K.J., Grim, J.N., Levecke, B. et al. (2013). Novel insights into the genetic diversity of Balantidium and Balantidium-like cyst-forming ciliates. PLoS Neglected Tropical Diseases. 7, pp. e2140.

Pomajbíková, K., Petrželková, K.J., Profousová, I. and Modrý, D. (2010). Discrepancies in the occurrence of Balantidium coli 
between wild and captive African great apes. Journal of Parasitology. 96, pp. 1139-1144.

Ponce-Gordo, F., Fonseca-Salamanca, F. and Martínez-Díaz, R.A. (2011). Genetic Heterogeneity in Internal Transcribed Spacer Genes of Balantidium coli (Litostomatea, Ciliophora). Protist. 162, pp. 774-794.

Ponce-Gordo, F., Jimenez-Ruiz, E. and Martínez-Díaz, R.A. (2008). Tentative identification of the species of Balantidium from ostriches (Struthio camelus) as Balantidium coli-like by analysis of polymorphic DNA. Veterinary Parasitology. 157, pp. 41-49.

Rees, C.W. (1927). Balantidia from pigs and guinea-pigs: their viability, cyst production and cultivation. Science. 66, pp. 89-91.

Růžicová, M., Petrželková, K.J., Kalousová, B., Modrý, D. and Pomajbíková, K. (2014). Validation of Flotac for the detection and quantification of Troglodytella abrassarti and Neobalantidium coli in chimpanzees and pigs. The Journal of Parisitology. 100, pp. 662-670.

Samad, M.A. (2011). Public health threat caused by zoonotic diseases in Bangladesh. Journal of Veterinary Medicine. 9, pp. 95-120.

Schovancová, K., Pomajbíková, K., Prochazka, P., Modrý, D., Bolechová, P. and Petrželková, K.J. (2013). Preliminary insights into the impact of dietary starch on the ciliate, Neobalantidium coli, in captive chimpanzees. Plos One.

Schumaker, E. (1930). Balantidium coli: host specificity and relation to the diet of an experimental host. American Journal of Hygiene. 12, pp. 341-365.

Schuster, F.L. and Ramirez-Avila, L. (2008). Current world status of Balantidium coli. Clinical Microbiology Reviews. 21, pp. 626-638.

Schuster, F.L. and Visvesvara, G.S. (2004). Amebae and ciliated protozoa as causal agents of waterborne zoonotic disease. Veterinary Parasitology. 126, pp. 91-120.

Sharma, S. and Harding, G. (2003). Necrotizing lung infection caused by the protozoan Balantidium coli. Canadian Journal of Infectious Diseases. 14, pp. 163-166.

Solaymani-Mohammadi, S., Rezaian, M. and Anwar, M.A. (2005). Human balantidiasis in Iran: an unresolved enigma?. Trends in Parasitology. 21, pp. 160-161.

Solaymani-Mohammadi, S., Rezaian, M. and Anwar, M.A. (2005). Response to Cox: Human balantidiasis in Iran: wild boars or not?. Trends in Parasitology. 21, pp. 554-555.

Solaymani-Mohammadi, S., Rezaian, M., Hooshyar, H., Mowlavi, G.R., Babaei, Z. and Anwar, M.A. (2004). Intestinal Protozoa in Wild Boars (Sus scrofa) in Western Iran. Journal of Wildlife Diseases. 40, pp. 801-803.

Stein, F. (1863). Ueber Paramecium (?) coli Malmsten. Chemische Berichte Deutsche Chemische Gesellschaft . 37, pp. 165. 
Tarrar, M.A., Khan, M.S., Pervez, K., Ashraf, K., Khan, J.A. and Rehman, Z.U. (2008). Detection and chemotherapy of Balantidium coli in buffaloes around Lahore, Pakistan. Pakistan Journal of Agricultural Sciences. 45, pp. 163-166.

Thompson, R.C.A. and Smith, A. (2011). Zoonotic enteric protozoa. Veterinary Parasitology. 182, pp. 70-78.

Vasilakopoulou, A., Dimarongona, K., Samakovli, A., Papadimitris, K. and Avlami, A. (2003). Balantidium coli pneumonia in an immunocompromised patient. Scandinavian Journal of Infectious Diseases. 35, pp. 144-146.

Walzer, P.D. and Healy, G.R. (1982). Balantidiasis. CRC Handbook Series in Zoonoses. Section C. Parasitic Zoonoses Editor in Chief: J. J. Steele. Vol. I. Ed. L. Jacobs and P. Arambulo. CRC Press, Inc. pp. 15-24.

Walzer, P.D., Judson, F.N., Murphy, K.B., Healy, G.R., English, D.K. and Schultz, M.C. (1973). Balantidiasis outbreak in Truk. American Journal of Tropical Medicine and Hygiene. 22, pp. 33-41.

Weng, Y.B., Hu, Y.J., Li, Y., Li, B.S., Lin, R.Q., Xie, D.H. et al. (2005). Survey of intestinal parasites in pigs from intensive farms in Guangdong Province, People's Republic of China. Veterinary Parasitology. 127, pp. 333-336.

WHO (1979). Parasitic zoonoses. Report of a WHO Expert Committee with the participation of FAO. World Health

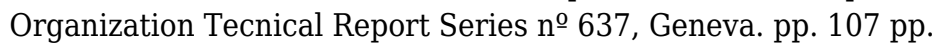

Yang, Y., Zeng, L., Li, M. and Zhou, J. (1995). Diarrhoea in piglets and monkeys experimentally infected with Balantidium coli isolated from human faeces. Journal of Tropical Medicine and Hygiene. 98, pp. 69-72.

Yatswako, S., Faleke, O.O., Gulumbe, M.L. and Daneji, A.I. (2007). Cryptosporidium oocysts and Balantidium coli cysts in pigs reared semi-intensively in Zuru, Nigeria. Pakistan Journal of Biological Sciences. 10, pp. 3435-3439.

Yazar, S., Altuntas, F., Sahin, I. and Atambay, M. (2004). Dysentery caused by Balantidium coli in a patient with nonHodgkin's lymphoma from Turkey. World Journal of Gastroenterology. 10, pp. 458-459.

Yin, D.M., Lv, C.C., Tan, L., Zhang, T.N., Yang, C.Z., Liu, Y. et al. (2015). Prevalence of Balantidium coli infection in sows in Hunan province, subtropical China. Tropical Animal Health and Production. 47, pp. 1637- 1640.

Zaman, V. (1978). Balantidium coli. Paratic Protozoa. ed J.P. Kreier ed.2, Academic Press. New York, USA. pp. 663-653. 